\title{
One Possible Cause for the Frequent Occurrence and Nonunion of Type II Odontoid Fracture
}

\section{Weixin Dong}

Ningbo No 6 Hospital

Yong Hu ( $\sim$ huyong610@163.com)

Department of Spinal Surgery, Ningbo No.6 Hospital, Ningbo 315040, People's Republic of China; Address: 1059 East Zhongshan Road, Ningbo, Zhejiang, 315040, P.R. China; https://orcid.org/0000-0003-3393-2413

Jian-bin Zhong

Ningbo No 6 Hospital

Zhen-shan Yuan

Ningbo No 6 Hospital

Bing-ke Zhu

Ningbo No 6 Hospital

Ou-jie Lai

Ningbo No 6 Hospital

Xiao-yang Sun

Ningbo No 6 Hospital

Research article

Keywords: CT, Bone density, Mimics, Odontoid fracture, Axis

Posted Date: September 21st, 2020

DOl: https://doi.org/10.21203/rs.3.rs-72289/v1

License: @ (i) This work is licensed under a Creative Commons Attribution 4.0 International License. Read Full License 


\begin{abstract}
Background. To analyze the underlying causes of frequent occurrence and nonunion of type II odontoid fracture.
\end{abstract}

Methods. CT scans along with 3D imaging software (Mimics software) were used to measure the bone density of the axis. The axis was divided into three parts, including the odontoid of the axis (the first part), the base of the odontoid (the second part) and the body of the axis (the third part). The CT value of the axis was measured and analyzed in different axial planes from top to bottom, followed by calculation and comparison of the mean CT value of the three parts of the axis.

Results. The mean CT value of the odontoid (the first part), base of the odontoid (the second part) and body of the axis (the third part) was $651.35 \pm 188.32$, $318.38 \pm 98.82$ and $397.45 \pm 93.59$, respectively. In addition, the interval variation of CT value of different axial planes was initially decreased and further increased with the change of axial planes from top to bottom.

Conclusion. The mean CT value of the base of the odontoid was significantly lower than that of the odontoid or the body of the axis. Therefore, the base of the odontoid was the transition region of shape and bone density, which may be one possible cause for the frequent occurrence and nonunion in the type II odontoid fracture in axis fracture.

\title{
Background
}

Odontoid fracture, first described by Mixter and Osgood in 1910, is the most prevalent fracture of the axis ${ }^{[1]}$, which is mainly categorized by Anderson and D'Alonzo classification $^{[2]}$. In addition, the type II odontoid fracture is the most prevalent type. Anderson and D'Alonzo ${ }^{[2]}$ reported 32 (54\%) and Greene et al ${ }^{[3]}$ revealed $120(60 \%)$ in their studies. However, the causes for the frequent occurrence and nonunion of type II odontoid fracture are complex and unclear. To this end, the current study aimed to explore the possible cause for frequent occurrence and nonunion of type II dens fractures.

\section{Methods \\ Inclusion and Exclusion Criteria}

CT images of 136 patients (73 males, 63 females, age: 19-87 (mean 52.35)) were randomly collected form the CT scan pool in our institution from February 2018 to February 2019. These enrolled patients were subjected to CT scanning (0.5 mm-thick/slice) of cervical spine (Philips Brilliance 64 CT, Philips Medical Systems, Amsterdam, Netherlands). Patients were eliminated from this study if they had: (1) CT scans after operation, (2) cervical spine with other pathological diagnosis, (3) tumor or infection, and (4) abnormal cervical anatomy. Our study was approved by Medical Ethics Committee of Ningbo No.6 Hospital and all investigations were conducted in conformity with ethical principles of research.

\section{Evaluation Of Ct Outcomes}

We first imported the volumetric imaging data preserved in digital imaging and communications in medicine format into Mimics 21.0. Software of Mimics 21.0 was used for the measurement of CT value and 3D reconstruction (Fig. 1). In terms of CT value measurement, the oval region of interest (ROI) was placed over an axial image of the axis (Fig. 1). Of note, the principle of ROI implantation was increasing trabecular bone as much as possible while avoiding the cortical bone as well as heterogeneous areas ${ }^{[4]}$. The mean CT value measured by Mimics 21.0 represented the bone density of the vertebral trabecular bone. The axis was divided into three parts, including the odontoid of the axis (the first part), the base of the odontoid (the second part) and the body of the axis (the third part) (Fig. 2). CT values of the axis were measured and analyzed in different axial planes from top to bottom, followed by calculation and comparison of the mean CT values of the three parts of the axis. Mimics software was adopted for the calculation of CT values (accuracy: $0.01 \mathrm{HU}$ ) and lengths (accuracy: $0.01 \mathrm{~mm}$ ). To be specific, CT images were magnified three times and assessed three times by every spine surgeon. Odontoid height of midsagittal plane was defined as $\mathrm{H} 1$, and the axial height of midsagittal plane was defined as $\mathrm{H} 2$ (Fig. 3).

\section{Statistical analysis}

SPSS version 17.0 (SPSS Inc, Chicago, IL, USA) was adopted for statistical analysis. Data were displayed as mean \pm standard deviation (SD) or ranges. Morphometric data were analyzed by Student's $t$ test, where a $P$ value of $<0.05$ indicated statistical significance. And gender difference was analyzed by twosample $t$ test with equal variances. In addition, ANOVA test along with post hoc SNK-q test was employed to compare the mean CT value of different parts for the axis.

\section{Results}

The mean CT value of the first part (the odontoid of the axis), the second part (the base of the odontoid) and the third part (the body of the axis) of the axis was $651.35 \pm 188.32$ (Table 1, Fig. 4), $318.38 \pm 98.82$ (Table 1, Fig. 4) and $397.45 \pm 93.59$ (Table 1, Fig. 4), respectively. In addition, the mean CT values of the three parts of the axis was statistically significant in males, females and total population (Table 2). In patients with 18-39 years of age, the mean CT value of the first, second and third part of the axis was $725.06 \pm 168.08$ (Table 3, Fig. 4), $360.6 \pm 82.83$ (Table 3, Fig. 4) and $455.87 \pm 70.34$ (Table 3, Fig. 4), respectively, which was statistically significant in different axis parts (Table 4). In patients with 40-59 years of age, the mean CT value of the first, second and third part of the axis was $694.23 \pm 176.38$ (Table 3, Fig. 4), $343.75 \pm 78.64$ (Table 3, Fig. 4) and 414.12 \pm 81.66 (Table 3, Fig. 4), respectively, which was significantly different (Table 4). Similarly, in patients with 60-90 years of age, the mean CT value of the first, second and third part of the axis was $589.89 \pm 186.06$

Page 2/10 
(Table 3, Fig. 4), $282.86 \pm 102.71$ (Table 3, Fig. 4) and 355.6 \pm 90.17 (Table 3, Fig. 4), respectively, with statistical significance in different axis parts (Table 4). The height of the axis at the sagittal plane was $32.44 \pm 2.37(26.98 \sim 39.09 \mathrm{~mm})$ (Table 5), and the height of the odontoid at the sagittal plane was $15.96 \pm$ 1.22 (13.09 $19.04 \mathrm{~mm}$ ) (Table 5). Therefore, the odontoid height was approximately equal to half of the axis height. Locally weighted scatter plot smoothing (LOESS) was used to show the mean values of CT value of the axis in different axial planes. Interval changes of CT value for the different axial planes were initially decreased and further increased from top to bottom in axial planes (Fig. 5).

Table 1 The CT value of different axis parts $\square^{\mathrm{X}} \pm \mathrm{S} \square$

\begin{tabular}{|llll|}
\hline & Odontoid & Surgical neck & Axis vertebral \\
\hline Male & $679.40 \pm 168.54$ & $333.95 \pm 91.54$ & $409.58 \pm 85.46$ \\
\hline Safe Range & $365.16 \sim 1084.44$ & $186.62 \sim 560.08$ & $229.39 \sim 594.77$ \\
\hline Safe Range & $253.05 \sim 1097.76$ & $51.37 \sim 558.76$ & $164.19 \sim 595.57$ \\
\hline Combined & $651.35 \pm 188.32$ & $318.38 \pm 98.82$ & $397.45 \pm 93.59$ \\
\hline Safe Range & $253.05 \sim 1097.76$ & $51.37 \sim 560.08$ & $164.19 \sim 595.57$ \\
\hline T & $\mathrm{t}=1.887$ & $\mathrm{t}=1.999$ & $\mathrm{t}=1.637$ \\
\hline $\mathrm{P}$ & $P=0.061$ & $P=0.048$ & $P=0.104$ \\
\hline
\end{tabular}

Table 2 Compare the mean CT value of different axis parts in males, females and total

\begin{tabular}{|c|c|c|c|c|c|c|c|c|c|}
\hline & Female & & & Male & & & Total & & \\
\hline subset $\neq$ & 1 & 2 & 3 & 1 & 2 & 3 & 1 & 2 & 3 \\
\hline b & 300.348 & & & 333. 950 & & & 318.384 & & \\
\hline c & & 383.393 & & & 409.577 & & & 397.448 & \\
\hline a & & & 618.854 & & & 679.404 & & & 651.355 \\
\hline$P t$ & 1.000 & 1.000 & 1.000 & 1.000 & 1.000 & 1.000 & 1.000 & 1.000 & 1.000 \\
\hline
\end{tabular}

tDerived with post hoc SNK (Student-Newman-Keuls)-q test for individual comparisons.

\#Different subsets have statistically significant $(P[0.05)$.

Table 3 The CT value of different axis parts ${ }^{\bar{x}} \pm \mathrm{S} \square$

\begin{tabular}{|c|c|c|c|c|c|c|c|c|}
\hline & $18-39$ years & & & 40-59 years & & & $60-90$ years & \\
\hline & Odontoid & Surgical neck & Axis vertebral & Odontoid & Surgical neck & Axis vertebral & Odontoid & Surgic: \\
\hline Male & $695.65 \pm 171.52$ & $358.92 \pm 75.44$ & $449.34 \pm 68.19$ & $666.29 \pm 167.99$ & $324.89 \pm 84.29$ & $386.02 \pm 86.93$ & $674.49 \pm 170.83$ & $322.5 \mathrm{C}$ \\
\hline $\begin{array}{l}\text { Safe } \\
\text { Range }\end{array}$ & $365.16 \sim 1084.44$ & $207.84 \sim 519.51$ & 298.29 590.25 & 388.77 934.2 & $191.21 \sim 526.86$ & 229.39 579.57 & $386.84 \sim 1035.25$ & 186.62 \\
\hline Female & $759.12 \pm 161.78$ & $362.55 \pm 92.73$ & $463.44 \pm 73.89$ & $720.18 \pm 186.17$ & $361.26 \pm 71.58$ & $440.21 \pm 69.55$ & $482.73 \pm 146.6$ & 232.53 \\
\hline $\begin{array}{l}\text { Safe } \\
\text { Range }\end{array}$ & $528.8 \sim 1097.76$ & $167.56 \sim 558.76$ & $335.88 \sim 595.57$ & $398.56 \sim 1064.29$ & $236.25 \sim 475.2$ & $337.52 \sim 594.08$ & $253.05 \sim 793.82$ & 51.37 \\
\hline Combined & $725.06 \pm 168.08$ & $360.60 \pm 82.83$ & $455.87 \pm 70.34$ & $694.23 \pm 176.38$ & $343.75 \pm 78.64$ & $414.12 \pm 81.66$ & $589.89 \pm 186.06$ & $282.8 \epsilon$ \\
\hline $\begin{array}{l}\text { Safe } \\
\text { Range }\end{array}$ & $365.16 \sim 1097.76$ & $167.56 \sim 558.76$ & 298.29 595.57 & $388.77 \sim 1064.29$ & $191.21 \sim 526.86$ & 229.39 594.08 & $253.05 \sim 1035.25$ & 51.37 \\
\hline $\mathrm{T}$ & $t=-1.213$ & $t=-0.138$ & $t=-0.636$ & $t=-0.787$ & $t=-1.211$ & $t=-1.795$ & $t=4.887$ & $t=3.96$ \\
\hline$P$ & $P=0.233$ & $P=0.891$ & $P=0.529$ & $P=0.438$ & $P=0.237$ & $P=0.085$ & $P=0.000$ & $P=0.0 C$ \\
\hline
\end{tabular}




\begin{tabular}{|llllllllll|}
\hline & $18-39$ & \multicolumn{7}{c|}{$40-59$} & \multicolumn{5}{c|}{$60-90$} \\
\hline subset $\neq$ & 1 & 2 & 3 & 1 & 2 & 3 & 1 & 2 & 3 \\
\hline b & 360.60 & & & 343.75 & & & 282.86 & \\
c & & 455.87 & & & 414.12 & & & 355.60 & \\
\hline a & & & 725.06 & & & 694.23 & & & 589.89 \\
Pt & 1.000 & 1.000 & 1.000 & 1.000 & 1.000 & 1.000 & 1.000 & 1.000 & 1.000 \\
\hline
\end{tabular}

tDerived with post hoc SNK (Student-Newman-Keuls)-q test for individual comparisons.

‡Different subsets have statistically significant $(P[0.05)$.

Table 5 The measurements of the axis and odontoid height $\mathrm{x} \pm \mathrm{S} \square(\mathrm{mm})$

\begin{tabular}{|llll|}
\hline & $\begin{array}{l}\text { Odontoid height } \\
(\mathrm{H} 1)\end{array}$ & $\begin{array}{l}\text { Axis height } \\
(\mathrm{H} 2)\end{array}$ & Ratio \\
\hline Male & $16.61 \pm 1.07$ & $33.81 \pm 1.98$ & $0.489 \pm 0.015$ \\
\hline Safe Range & $14.15 \sim 19.04$ & $28.88 \sim 39.09$ & $0.438 \sim 0.5155$ \\
\hline Female & $15.20 \pm 0.92$ & $30.85 \pm 1.71$ & $0.496 \pm 0.015$ \\
\hline Safe Range & $13.09 \sim 17.32$ & $26.98 \sim 34.12$ & $0.451 \sim 0.540$ \\
\hline Combined & $15.96 \pm 1.22$ & $32.44 \pm 2.37$ & $0.492 \pm 0.015$ \\
\hline Safe Range & $13.09 \sim 19.04$ & $26.98 \sim 39.09$ & $0.438 \sim 0.540$ \\
\hline T & $\mathrm{t}=8.155$ & $\mathrm{t}=9.258$ & $\mathrm{t}=-2.558$ \\
\hline $\mathrm{P}$ & $P=0.000$ & $P=0.000$ & $P=0.012$ \\
\hline
\end{tabular}

\section{Discussion}

Type II dens fractures account for approximately two-thirds of all odontoid fractures. Type II odontoid fractures are generally detected at odontoid-body junction base, with complicated influencing factors. Apart from morphological appearance, the lowest bone density within the axis is likely to be another significant factor causing type II fractures. The current study aimed to analyze the possible causes of the frequent occurrence and nonunion of type II odontoid fracture.

\section{The factors causing high incidence of type II odontoid fracture}

Odontoid fractures accounts for approximately $60 \%$ of all axis fractures and $10-18 \%$ of all cervical spine fractures ${ }^{[3,5,6]}$. The type II odontoid fracture is reported as the most prevalent dens fracture. Moreover, type II dens fractures also consists of about two-thirds of all odontoid fractures ${ }^{[7]}$. Greene et al ${ }^{[3]}$ revealed $120(60 \%)$ in their study, while Anderson and D'Alonzo ${ }^{[2]}$ reported 32 (54\%). Moreover, it remains controversial of the fracture etiology. Amling et al ${ }^{[8]}$ reported that cortex thickness at dens base is only $35 \%$ of dens or one-third of the axis in both normal and osteoporosis individuals. According to Wang et al[9], the above anatomically distinct parameters might play critical roles in the mechanism of type II fractures. The mean CT value of the base of the odontoid (318.38 \pm 98.82$)$ was significantly lower than that of the odontoid (397.45 \pm 93.59$)$ and the body of the axis $(651.35 \pm 188.32)$. Moreover, odontoid base is the conjunct region between the body of the axis and odontoid, which is revealed as the transition region of shape and bone density within the axis. Amling et $\mathrm{al}^{[10]}$ reported that dens base is the region of least resistance for fractures due to poorer trabecular interconnection as well as decreased trabecular bone volume. The trabecular microarchitecture further revealed that trabecular number as well as bone volume was significantly decreased, while trabecular separation was increased within dens base, in comparison with the dens or corpus of $\mathrm{C} 2$, which might explain the frequent occurrence of type II dens fractures ${ }^{[10]}$. Histological investigation revealed poor trabecular interconnection of subdental synchondrosis within surrounding cancellous bone ${ }^{[11]}$. Wang et $\mathrm{a}^{\left[{ }^{[9]}\right.}$ demonstrated that the odontoid base had reduced bone volume fractions due to its micro-architectural weak points. Wang et al ${ }^{[9]}$ cautiously speculated that higher probability of type II fractures at the base of the odontoid junction because of load-bearing pillars role of radial rodlike trabecular for force transmission from plate-like trabeculae running parallel to articular surfaces. In the case of convergence and transmission of energy to the weakest trabecular bone, tear would occur first. The energy is transmitted along the torn trabecular bone to eventually cause fractures due to the heavy burden. Interval changes of CT value for the different axial planes were first decreased and then increased from top to bottom in the axial planes. These may be the possible cause reasons for the frequent occurrence of type II odontoid fracture.

The possible reasons for frequent nonunion of type Il odontoid fracture

Page $4 / 10$ 
In this paper, the type II odontoid fracture was named as surgical neck fracture of the axis based on two factors. The first reason was that type II odontoid fracture was located at the axis transition region, which looked like the neck of the axis. The second reason was the frequent occurrence of nonunion in type II odontoid fracture in the case of conservative treatment ${ }^{[12]}$. The nonunion incidence of type-Il fractures following conservative therapy is reported to range between $15 \%$ and $85 \%[12,13]$. Nonunion of type II odontoid fracture is caused by a variety of factor, among which, disrupted blood supply due to trauma has been considered to make great contribution ${ }^{[14,15]}$. Some studies have suggested that disrupted blood supply in odontoid process also contributes nonunion as well as avascular necrosis ${ }^{[14,16,17]}$. However, some anatomical researches have revealed vascular arcade of the odontoid process as well as body of the axis $^{[18-20]}$, therefore, blood supply is not disrupted in the odontoid process in the case of type-ll fractures. Some studies have shown the deficient bone mass as well as an inadequate number of trabeculae at the odontoid process base, which might be another possible reason for the frequent nonunion following type-Il fractures. Amling et al ${ }^{[8]}$ reported a $55 \%$ decrease on mean volume of trabeculae at the odontoid process base over the odontoid process and axis. Amling et $\mathrm{al}^{[10]}$ reported that reparative callus following fractures mainly initiated from fractured trabeculae, thus, cancellous bone recovered faster than cortical bone. Regardless of the healthy status of the bone, the bone volume is significantly decreased in the base of odontoid process than dens as well as the body of axis, with a lack of sufficient starting point for reparative callus, which may be one of the possible reason underlying the high incidence of nonunion within the type II odontoid fracture ${ }^{[8]}$. In this study, the mean CT value of the base of the odontoid (318.38 \pm 98.82$)$ was significantly lower than the odontoid (397.45 \pm 93.59$)$ and the body of the axis $(651.35 \pm 188.32)$. Govender et al ${ }^{[12]}$ reported that the mean difference of surface area between type-II and type-III fractures was $134.72 \mathrm{~mm}^{2}$, which might influence healing after fracture. Iwanaga et al ${ }^{[21]}$ and Heggeness et al ${ }^{[22]}$ reported that the odontoid process was under destructive forces from the apical ligament, which can lead to nonunion of type II odontoid fracture. Crockard et al ${ }^{[23]}$ and Moskovich et al ${ }^{[24]}$ suggested that the occurrence of nonunion in type-II fractures as a consequence of the interposition of the transverse ligament at the site of the fracture.

\section{Conclusion}

The mean CT values of the odontoid and the body of the axis were significantly higher than that of odontoid base. The conjunct region between the odontoid and the body of the axis was the transition region of shape and bone density, which may be the possible cause for the frequent occurrence and nonunion in the type II odontoid fracture.

\section{Abbreviations}

CT: Computed tomography; ROI: Region of interest; SD: Standard deviation; ANOVA: Analysis of Variance; LOESS: Locally weighted scatter plot smoothing;

\section{Declarations}

\section{Ethics approval and consent to participate}

Our study was approved by the Regional Ethics committee of Ningbo No.6 Hospital and all investigations were conducted in conformity with ethical principles of research.

\section{Consent for publications}

Not applicable.

\section{Availability of data and materials}

The dataset used during the current study are available from the corresponding author on reasonable request.

\section{Competing Interest}

The authors declare that they have no competing interests.

\section{Funding}

No funds were received in support of this work.

\section{Authors' contributions}

WXD and YH: Responsible for the design and planning of the study. WXD: the drafting of the first manuscript with contributions from the other authors. All authors were involved in the preparation and planning of the data analyses. All authors read and approved the final manuscript.

\section{Acknowledgements}

We thank William Ryan Spiker performed the language editing of this article.

\section{References}

1. Mixter SJ, Osgood RB. Traumatic Lesions of the Atlas and Axis. Ann Surg. 1910;51:193-207.

2. Anderson LD, D'Alonzo RT. Fracture of the Odontoid Process of the Axis. J Bone Joint Surg Am. 1974;56:1663-74. 
3. Greene KA, Dickman CA, Marciano FF, et al. Acute axis fractures. Analysis of management and outcome in 340 consecutive cases. Spine. 1997;22:184352.

4. Zou D, Li W, Deng C, et al. The use of CT Hounsfield unit values to identify the undiagnosed spinal osteoporosis in patients with lumbar degenerative diseases. Eur Spine J. 2019;28:1758-66.

5. Vaccaro AR, Madigan L, Ehrler DM. Contemporary management of adult cervical odontoid fractures. Orthopedics. 2000;23:1114-5.

6. Lee PC, Chun SY, Leong JC. Experience of posterior surgery in atlanto-axial instability. Spine. 1984;9:231-9.

7. Hart R, Saterbak A, Rapp T, et al. Nonoperative management of dens fracture nonunion in elderly patients without myelopathy. Spine. 2000;25:1339-43.

8. Amling M, Hahn M, Wening VJ, et al. The microarchitecture of the axis as the predisposing factor for fracture of the base of the odontoid process. A histomorphometric analysis of twenty-two autopsy specimens. J Bone Joint Surg Am. 1994;76:1840-6.

9. Wang W, Li Z, Qi Y, et al. Micro-architecture study of the normal odontoid with micro-computed tomography. J Spinal Cord Med. 2020;43:211-6.

10. Amling M, Pösl M, Wening VJ, et al. Structural heterogeneity within the axis: the main cause in the etiology of dens fractures. A histomorphometric analysis of 37 normal and osteoporotic autopsy cases. J Neurosurg. 1995;83:330-5.

11. Gebauer M, Lohse C, Barvencik F, et al. Subdental synchondrosis and anatomy of the axis in aging: a histomorphometric study on 30 autopsy cases. Eur Spine J. 2006;15:292-8.

12. Govender S, Maharaj JF, Haffajee MR. Fractures of the odontoid process. J Bone Joint Surg Br. 2000;82:1143-7.

13. Sasso RC. C2 dens fractures: treatment options [J]. J Spinal Disord. 2001;14:455-63.

14. Apuzzo ML, Heiden JS, Weiss MH, et al. Acute fractures of the odontoid process. An analysis of 45 cases. J Neurosurg. 1978;48:85-91.

15. Geisler FH, Cheng C, Poka A, et al (1989) Anterior screw fixation of posteriorly displaced type II odontoid fractures [J]. Neurosurgery, 25 : 30-37.

16. Schatzker J, Rorabeck CH, Waddell JP, et al. Fractures of the dens (odontoid process). An analysis of thirty-seven cases. J Bone Joint Surg Br. 1971;53:392-4.

17. Southwick WO. Management of fractures of the dens (odontoid process). J Bone Joint Surg Am. 1980;62:482-6.

18. Schiff DC, Parke WW. The arterial supply of the odontoid process [J]. J Bone Joint Surg Am. 1973;55:1450-6.

19. Althoff B, Goldie IF. The arterial supply of the odontoid process of the axis [J]. Acta Orthop Scand. 1977;48:622-9.

20. Schatzker J, Rorabeck CH, Waddell JP. Non-union of the odontoid process. An experimental investigation [J]. Clin Orthop Relat Res. 1975;5:127-37.

21. Iwanaga J, Sardi JP, Laws T, et al. Anatomy of Alar Ligament Part III: Biomechanical Study. World Neurosurg. 2017;107:1012-5.

22. Heggeness MH, Doherty BJ. The trabecular anatomy of the axis. Spine. 1993;18:1945-9.

23. Crockard HA, Heilman AE, Stevens JM. Progressive myelopathy secondary to odontoid fractures: clinical, radiological, and surgical features. J Neurosurg. 1993;78:579-86.

24. Moskovich R, Crockard HA. Myelopathy due to hypertrophic nonunion of the dens: case report. J Trauma. 1990;30:222-5.

\section{Figures}



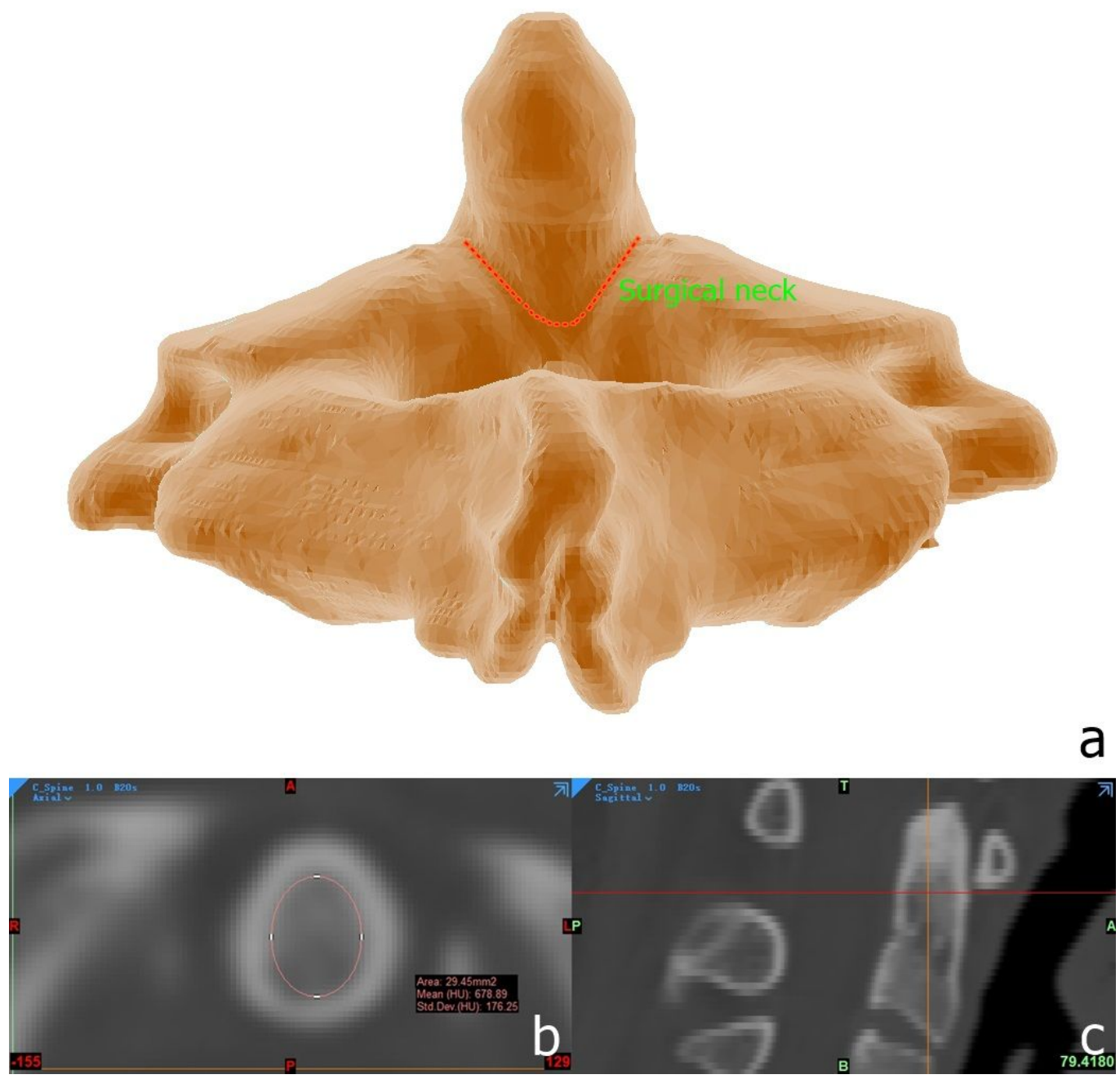

Figure 1

$\mathrm{a}$, The surgical neck of the axis. b and c,the CT value was measured by placing an oval region of interest (ROI) over an axial image of the axis 


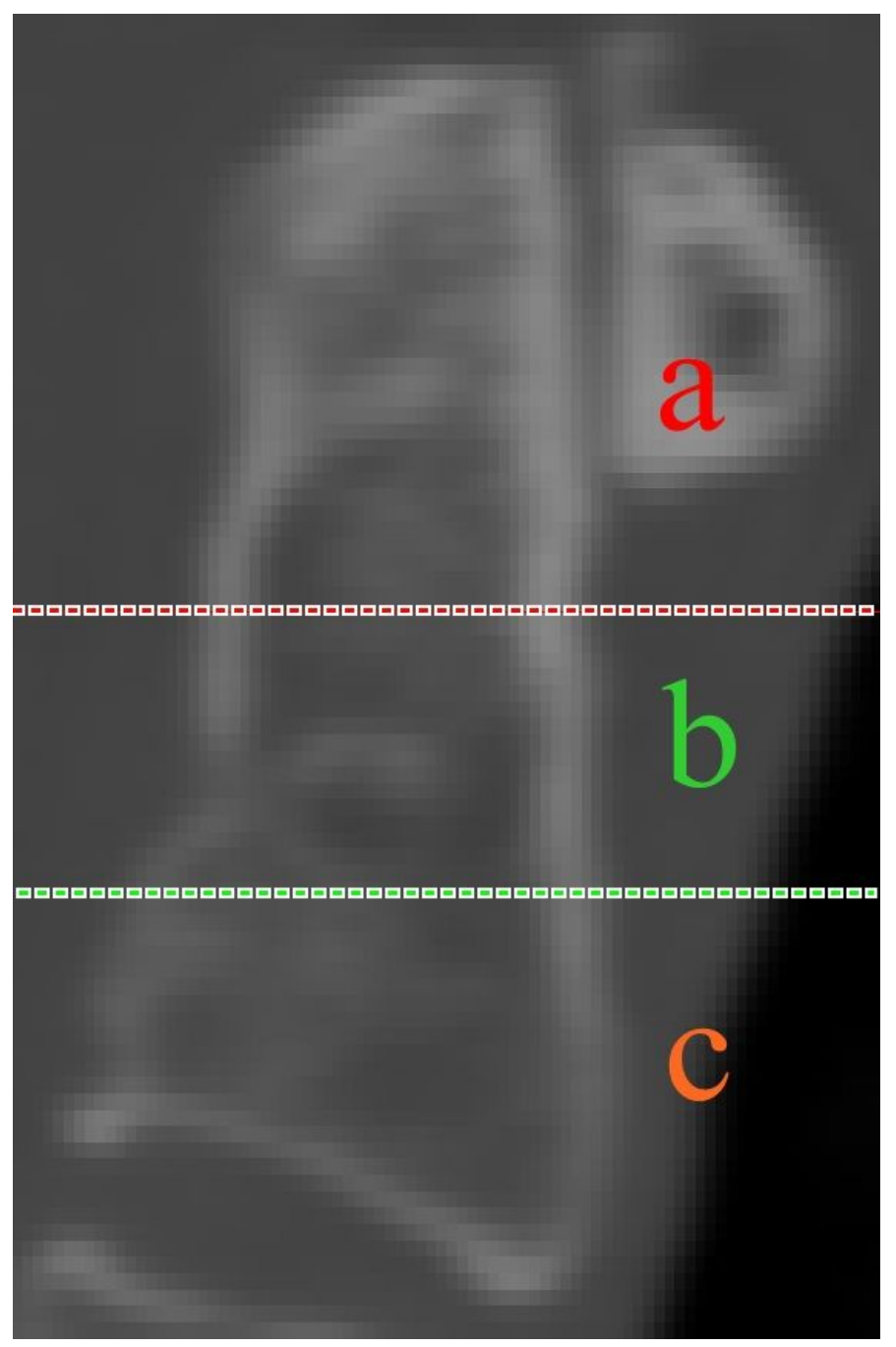

\section{Figure 2}

The axis was divided into three parts. a, the first part was the odontoid of the axis. b,the second part was the base of the odontoid. c, the third part was the body of the axis. 


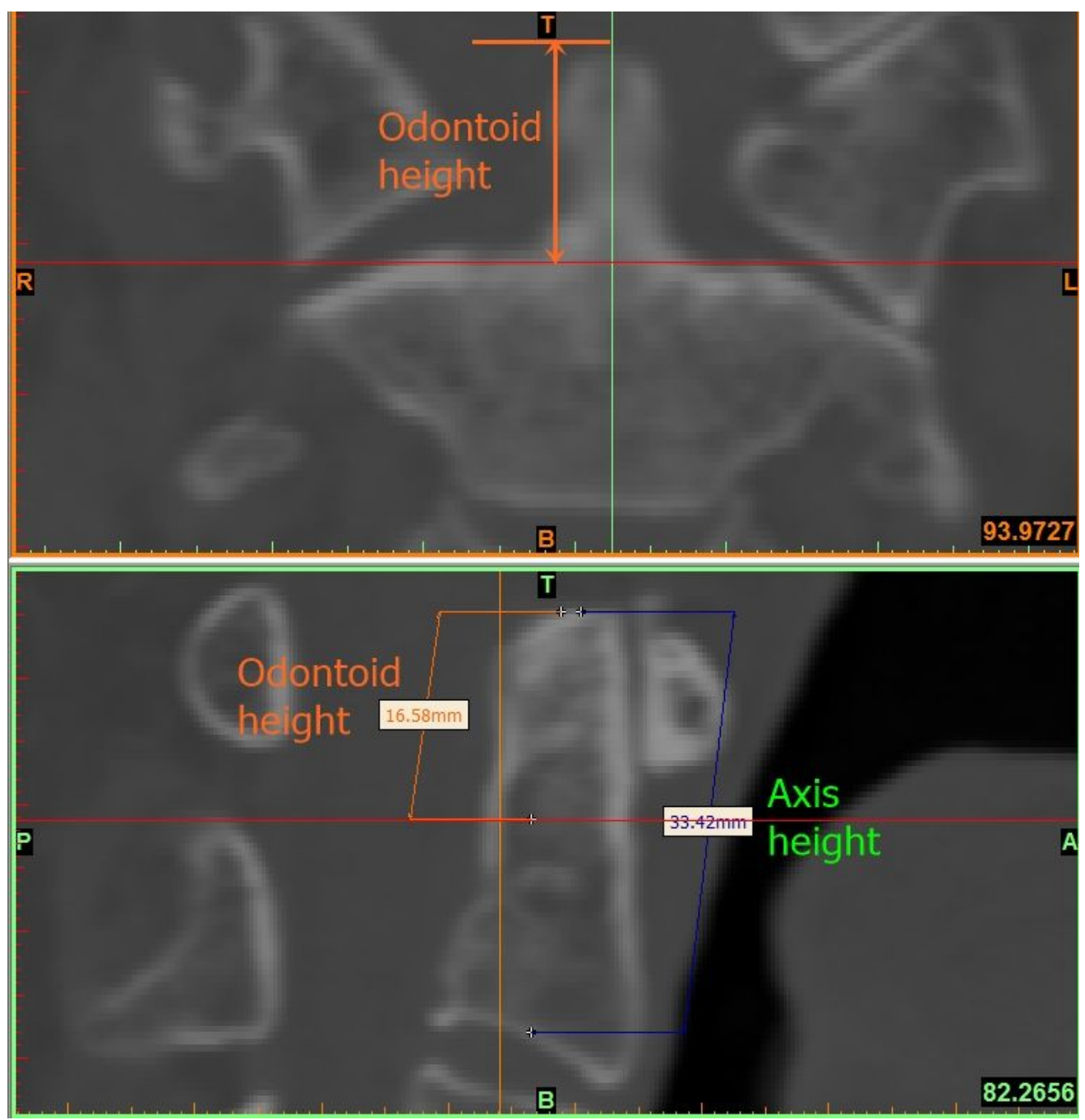

\section{Figure 3}

The height of the axis and odontoid
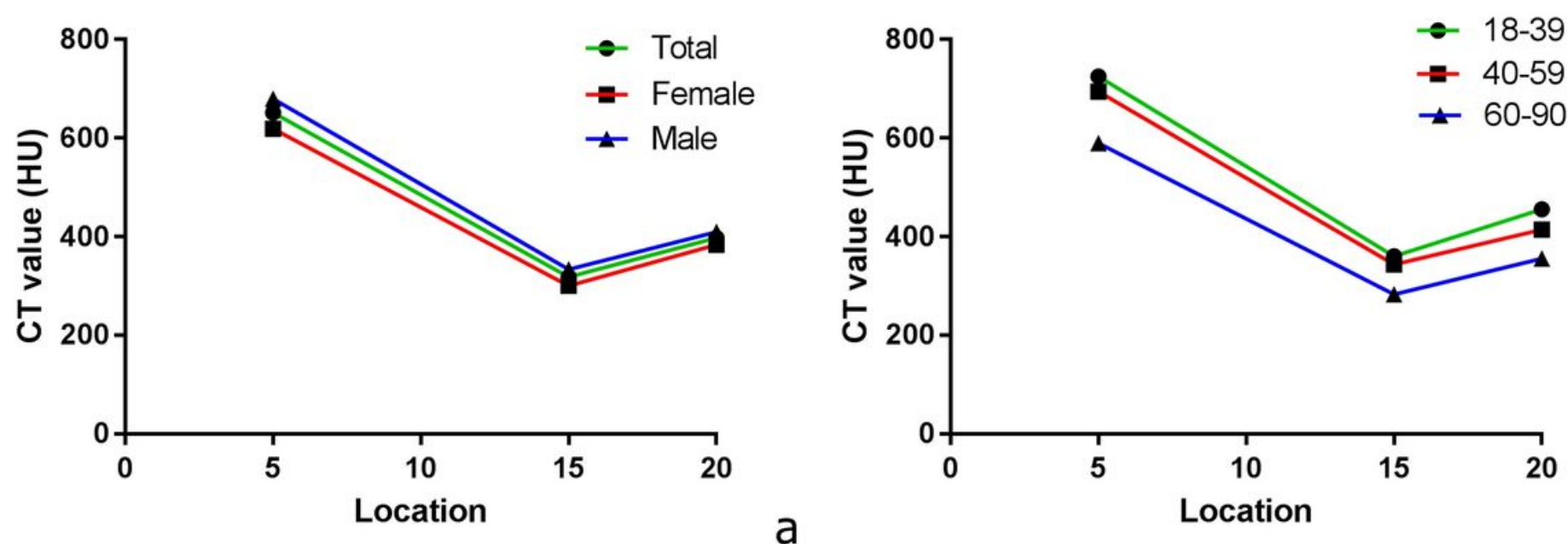

b

Figure 4

a, Scatter plot showing the mean CT value of the axis three parts in males, females and total. b, Scatter plot showing the mean CT value of the axis three parts at different ages. 


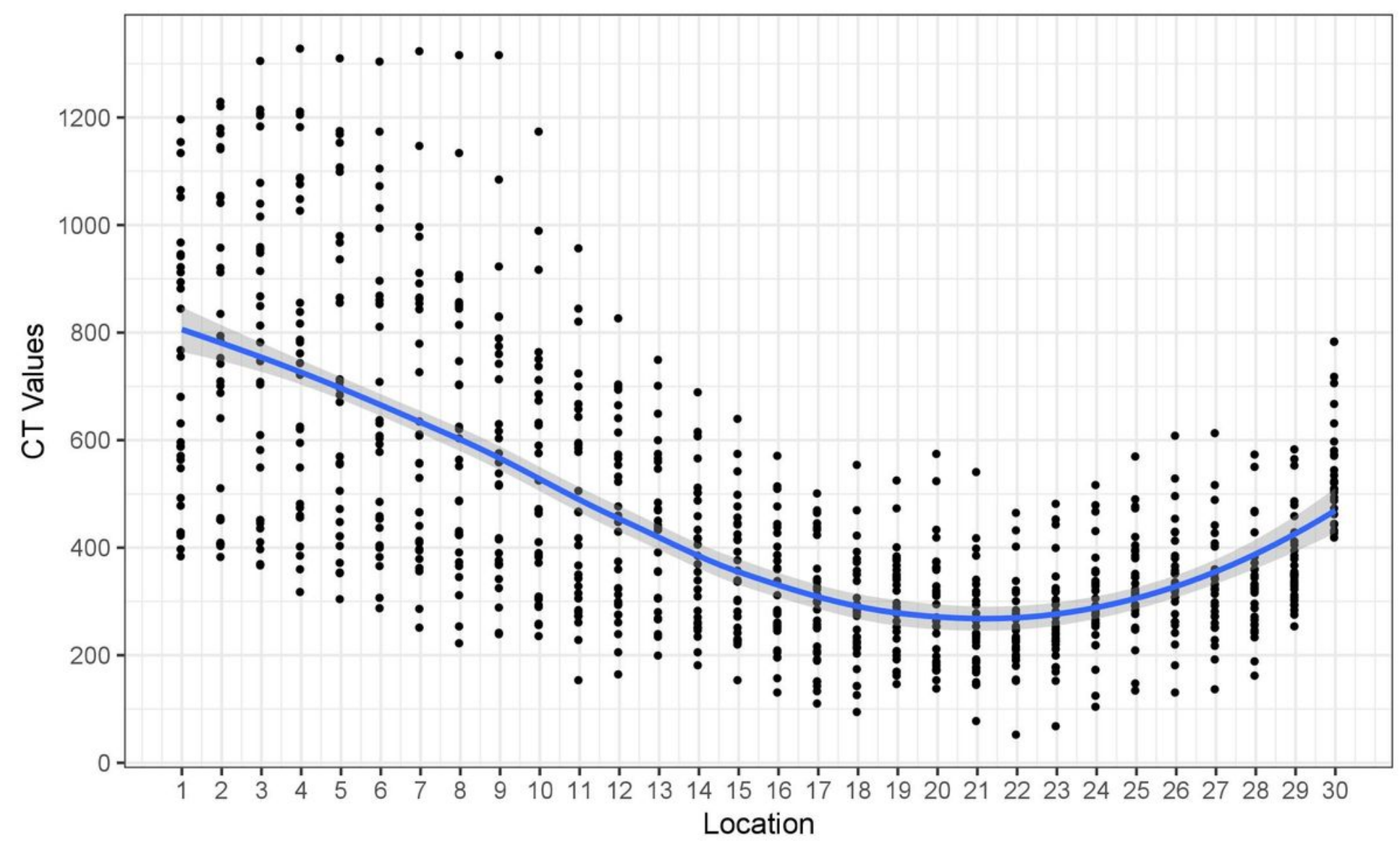

Figure 5

Locally weighted scatterplot smoothing (LOESS) showing the mean values of CT value of the axis in the different axial plane 